\title{
Smilacis Glabrae Rhizoma Reduces Oxidative Stress Caused by Hyperuricemia via Upregulation of Catalase
}

\author{
Quan Hong Shandong Yu Yan Mei Yang Lv Dapeng Chen Yuanda Wang \\ Wenjia Geng Di Wu Guangyan Cai Xiangmei Chen
}

Department of Nephrology, Chinese PLA General Hospital, Chinese PLA Institute of Nephrology, State Key Laboratory of Kidney Diseases, National Clinical Research Center of Kidney Diseases; Beijing, P.R. China

\section{Key Words}

Hyperuricemia • Bioinformatic analysis $•$ Smilacis Glabrae Rhizoma • Oxidative stress $•$ Catalase

\begin{abstract}
Background/Aims: Reports have suggested that the traditional Chinese medicine Smilacis Glabrae Rhizoma attenuates hyperuricemia, but its mechanism is unclear. Our previous study demonstrated that uric acid could induce the generation of reactive oxygen species(ROS), which subsequently cause endothelial dysfunction. Therefore, we focused on the oxidative stress process. In this study, we would use LC-MS and bioinformatic analysis to investigate the underlying mechanism. Methods: We utilized LC-MS to reveal the differential protein expression in the kidneys of rats in the hyperuricemia group and the Smilacis Glabrae Rhizoma treatment group and then subjected the differentially expressed proteins to bioinformatic analysis. We also determined the serum ROS level of the two groups. According the above results, we built our hypothesis and performed in vitro experiments to validate this hypothesis. Results: We found that catalase was upregulated in the group treated with Smilacis Glabrae Rhizoma, and the level of reactive oxygen species was higher in the hyperuricemia group. Thus, we speculated that Smilacis Glabrae Rhizoma could alleviate oxidative stress by upregulating catalase. In vitro experiments, we found that high concentrations of uric acid reduced catalase expression in endothelial cells, which was alleviated by Smilacis Glabrae Rhizoma and resulted in a reduction of reactive oxygen species. Knockdown of catalase led to an increase in reactive oxygen species. Conclusion: We demonstrated that Smilacis Glabrae Rhizoma could alleviate the oxidative stress caused by hyperuricemia by upregulating catalase expression. This finding could represent a new application for Smilacis Glabrae Rhizoma in the treatment of hyperuricemia.
\end{abstract}




\section{Cellular Physiology and Biochemistry}

Cell Physiol Biochem 2014;34:1675-1685

\begin{tabular}{l|l}
\hline DOI: $10.1159 / 000366369$ & (C) 2014 S. Karger AG, Basel
\end{tabular}

www.karger.com/cpb

Hong et al.: SGR Reduces Oxidative Stress of ECs via Upregulation of Catalase

\section{Introduction}

Hyperuricemia is a common disease. Numerous studies have confirmed that hyperuricemia is an independent risk factor for chronic kidney disease (CKD) and cardiovascular disease (CVD) [1-4]. Therefore, investigating ways to control serum uric acid levels has become a topic of great interest.

Interest in the use of traditional Chinese medicine (TCM) for the treatment of hyperuricemia has grown in recent years [5, 6]. Many TCM remedies contain Smilacis Glabrae Rhizoma (SGR), which belongs to the Smilacaceae family and the Smilax genus. SGR has been found to be effective for the treatment of xeransis, for detoxification, and for easing joint movement in the TCM literature, including the Compendium of Materia Medica and the State Pharmacopoeia of the People's Republic of China. Hu et al reported that a Simiao pill could reduce elevated serum uric acid (UA) levels and alleviate renal injury caused by hyperuricemia [7]. However, the mechanism of its protective effects on renal function under hyperuricemic conditions is not known. It has been demonstrated that the production of reactive oxygen species (ROS) increased significantly under hyperuricemic conditions [8], and our previous studies $[9,10]$ and other research [11-14] have confirmed that high concentrations of uric acid could cause endothelial dysfunction by generating reactive oxidative species (ROS), which induce calcium overload and inflammation. It has also been reported that high concentrations of uric acid could induce renal failure by damaging endothelial cells [15], but the underlying mechanism remains unclear. Given the above research, we hypothesized that, to some extent, hyperuricemia causes renal injury by increasing the ROS that damage endothelial cells. SGR could play a protective role for the kidneys by diminishing ROS production, thereby ameliorating endothelial damage. In this study, we used label-free quantitative liquid chromatography mass spectrometry (Label-free LC-MS/MS) to analyze protein expression in the kidneys of control rats and hyperuricemic rats that were treated with SGR. Of the differentially expressed proteins, catalase is noteworthy because it is responsible for the degradation of hydrogen peroxide [16], and it is a protective enzyme that is present in nearly all animal cells [17-19]. In this study, we also demonstrated that catalase could be upregulated by SGR and that it reduced the generation of ROS that were induced by high concentrations of uric acid in vitro.

\section{Materials and Methods}

\section{Materials and reagents}

The dried rhizome of SGR was purchased from the Beijing Tong Ren Tang Pharmacy (Beijing, China). Ethyl alcohol and methanol (analytical grade) were purchased from the Beijing Chemical Reagent Company. Allopurinol (its purity exceeded $99.2 \%$, as determined by HPLC), uric acid and oxonic acid were purchased from Sigma-Aldrich (St Louis MO. USA). Assay kits for uric acid ROS were obtained from Jiancheng Biotech (Nanjing, China).

\section{Establishment of hyperuricemic rat models}

Hyperuricemic rat models were established as described by Yang et al. [20, 21], with slight modifications. The animal protocol was reviewed and approved by the Institutional Animal Care and Use Committee of the Chinese PLA General Hospital. Sprague Dawley (SD) rats, obtained from the Experimental Animal Center of Academy of Military Medical Sciences (China), were housed in temperature-controlled cages on a $12 \mathrm{~h}$ light-dark cycle and were given free access to water and normal chow. After 1 week of breeding for adaptation, the rats were grouped into control $(n=8)$ and hyperuricemic $(n=8)$ groups. The rats were injected intraperitoneally with $250 \mathrm{mg} / \mathrm{kg} \cdot \mathrm{d}$ of oxonic acid potassium salt (Sigma) and $250 \mathrm{mg} / \mathrm{kg} \cdot \mathrm{d}$ of uric acid (Sigma). Fourteen days after modeling, the levels of UA in the blood were evaluated. Then, the rats were orally administered a solution with or without $1 \mathrm{~mL}$ of SGR $(1 \mathrm{~g} / \mathrm{mL})$ every day for the subsequent four weeks. 


\section{Cellular Physiology and Biochemistry}

Cell Physiol Biochem 2014;34:1675-1685

\begin{tabular}{l|l}
\hline DOI: $10.1159 / 000366369$ & (c) 2014 S. Karger AG, Basel
\end{tabular}

www.karger.com/cpb

Hong et al.: SGR Reduces Oxidative Stress of ECs via Upregulation of Catalase

LC-MS and data processing

LC-MS was performed as described previously $[22,23]$. Continuum LC-MS data were processed and searched using Protein Lynx Global Server software, version 2.4 (Waters Corp.), with Expression software, version 2 (Waters Corp.). During the data preparation, the low- and elevated-energy thresholds were set at 100 and 50, respectively. In the workflow, fixed modification was set as carbamidomethyl (C) and variable modification as oxidation (M). The default settings were used for all the other parameters. The NCBI rat database (released March 2012) was used for protein identification. Quantitative analyses were performed using the protein expression module in PLGS software, version 2.5. The entire data set of differentially expressed proteins was further filtered by considering only those identified from the alternate scanning LC-MSE data, with the identified peptides exhibiting a good replication rate (two out of three injections). The threshold for statistical significance of a regulation level was set at a 2 -fold change with a P-value $<0.05$. The data analysis was completed by http://www.uniprot.org and http://www.capitalbio. com/zh-hans/ support/MAS3.

\section{Pathway analysis}

Pathway analysis was used to determine the significant pathways that involved the differential genes, according to KEGG and Genemap [24, 25]. Fisher's exact test and the $x^{2}$ test were used to classify the GO category, and the false discovery rate (FDR) was calculated to correct the P-value. A smaller FDR indicated a smaller error in judging the P-value. The FDR was defined as $F D R=1-\frac{N_{k}}{T}$, where $N_{k}$ refers to the number of Fisher's test P-values that are less than the $x^{2}$ test P-values. We computed P-values for the pathways of all of the differentially expressed proteins. Enrichment provided a measure of the significance of the function: as the enrichment increased, the corresponding function was more specific, which helped us to find those GOs that had more concrete functional descriptions in the experiment. Within the significant category, the enrichment, Re, was given by: $\operatorname{Re}=\left(n_{f} / n\right) /\left(N_{f} / N\right)$, where $n_{f}$ is the number of differential proteins within the particular category, $n$ is the total number of proteins within the same category, $N_{f}$ is the number of differential proteins in the entire microarray, and $N$ is the total number of proteins in the LC-MS.

\section{Cell culture}

Human umbilical vein endothelial cells (HUVECs) were purchased from ATCC (No. CRL-1730) and were cultured in RPMI-1640 medium supplemented with $10 \%$ fetal bovine serum (FBS) at $37^{\circ} \mathrm{C}$ in a humidified incubator in an atmosphere containing $5 \% \mathrm{CO}_{2}$.

Western blot assay

RIPA lysis buffer (containing $50 \mathrm{mmol} / \mathrm{L}$ Tris- $\mathrm{HCl}$ at $\mathrm{pH}$ 7.5, $150 \mathrm{mmol} / \mathrm{L} \mathrm{NaCl}, 0.5 \%$ deoxycholate, $1 \%$ Nonidet P-40, $0.1 \%$ SDS, $1 \mathrm{mM}$ PMSF, and a variety of protease inhibition agents at $1 \mu \mathrm{g} / \mathrm{mL}$ ) was used to extract the proteins. The tissue lysate was taken to determine the concentrations of proteins using a BCA kit. Approximately $80 \mu \mathrm{g}$ of protein was used for 10\% SDS-PAGE and then was transferred to a PVDF membrane, which was kept overnight in a $5 \%$ no-milk solution at $4{ }^{\circ} \mathrm{C}$ after Ponceau S staining. The membrane was incubated in primary antibodies (Santa Cruz Biotechnology, Santa Cruz, CA, USA). The blots were developed with an ECL reagent (Santa Cruz Biotechnologies) according to the manufacturer's instructions and were exposed to X-ray film. The protein bands were quantified using Quantity One software (Bio-rad).

\section{Small interfering RNA (siRNA) transfection}

Catalase siRNA (100 nM, sc-29204, Santa Cruz Biotechnology) was transfected into HUVECs using the RNAi MAX transfection reagent, according to the manufacturer's instructions (Invitrogen). A non-silencing siRNA was used as the negative control. Forty-eight hours after transfection, the cells were starved for $16 \mathrm{~h}$ and then were treated with or without UA.

\section{Measurement of total intracellular ROS}

The changes in intracellular ROS were detected with CM-H ${ }_{2}$ DCFDA oxidant-sensing fluorescent probes, at a final concentration of $10 \mu \mathrm{mol} / \mathrm{L}$. Fluorescence images were obtained with a laser confocal system mounted on an inverted microscope and equipped with an argon-krypton laser. For studies using CM- $\mathrm{H}_{2}$ DCFDA, an excitation wavelength of $488 \mathrm{~nm}$ (argon laser) and an emission wavelength of $515 \mathrm{~nm}$ were used. 


\section{Cellular Physiology and Biochemistry}

Cell Physiol Biochem 2014;34:1675-1685

\section{Statistical analysis}

The results are presented as the means \pm SDs. The data were analyzed using one-way analysis of variance plus Bonferroni's correction (Student-Newman-Keuls). P-values less than 0.05 were considered statistically significant.

\section{Results}

\section{LC-MS/MS data}

We obtained 102 different proteins from our software analysis, 72 of which were significantly different between the SGR treatment group and the group with high concentrations of uric acid (HUA). Table 1 displays all of the differentially expressed proteins $(\mathrm{P}<0.05)$. In total, 40 proteins were upregulated and 32 were downregulated (Table 1$)$.

\section{GO (Gene ontology) analysis}

GO analysis was applied to analyze the main functions of the differentially expressed proteins, using the UniProt workstation, according to Gene Ontology, the key functional classification of NCBI. This analysis revealed that there were 68 proteins that participated in biological processes, 69 proteins that belonged to the cellular component domain and 71 proteins that participated in molecular function (Fig. 1A). The subclassification of the proteins in the biological process domain included cellular processes (65 proteins), metabolic processes (53), single-organism processes (52), biological regulation (34) and others. (Fig. 1B). The subclassification of the proteins in the cellular components domain included cell parts (67), organelles (60), organelle parts (42), membranes (33) and others (Fig. 1C). The subclassification of the proteins in the molecular function domain included binding (66), catalytic (47), oxidoreductase (25), transporter (18) and other functions (Fig. 1D).

\section{Pathway analysis}

Pathway analysis indicated that the KEGG pathway included proteins related to leukocyte transendothelial migration, actin cytoskeleton regulation, focal adhesion, adherent junctions, tight junctions and others. The GenMAPP pathway included proteins related to striated muscle contraction (physiological processes), motor activity (molecular function), oxidoreductase activity (molecular function), extracellular space (cellular component), and enzyme inhibitor activity (molecular function). The top 10 significant pathways for KEGG and GenMAPP are listed in Tables 2 and 3, and the pathway maps are shown in http://www. rayfile.com/en/files/6615d5eb-5830-11e4-bfe0-0015c55db73d/ca8106d7/.

\section{Analyses of catalase protein}

Because our previous study demonstrated that uric acid could induce ROS generation that subsequently caused endothelial dysfunction [9], we focused on the oxidative stress process in this study. Based on our gene-pathway and GO-protein networks (supporting information), we noticed that catalase (CAT) was related to oxidative stress and was upregulated approximately 6.4-fold more in the SGR treatment group than in the HUA group. GO analysis indicated that catalase contained 30 significant GO terms, such as a response to reactive oxygen species, aminoacylase activity and others. All of the GO terms are listed in Table 4. There were 8 significant pathways related to catalase, including tryptophan metabolism, oxidative stress, methane metabolism, iron ion binding, amyotrophic lateral sclerosis (ALS), tryptophan metabolism, oxidoreductase activity, and electron transport.

SGR could induce catalase upregulation and decrease ROS generation

We confirmed that catalase expression was higher in the SGR treatment group than in the hyperuricemia group using western blotting (Fig. 2A). Serum ROS in the SRG treatment group was lower than that in the hyperuricemia group (Fig. 2B). Additionally, catalase expression 
Table 1. 72 proteinsshowed significant differences between SGR treatment group and HUA group

\begin{tabular}{|c|c|c|c|}
\hline Uniprot ID & Symbol & Protein names & $\begin{array}{c}\text { SGR/model } \\
\text { Ratio }\end{array}$ \\
\hline \multicolumn{4}{|c|}{ Downregulated } \\
\hline 035078 & B0BNJ4 & Ethylmalonic encephalopathy 1 & 0.0309 \\
\hline D8NU12 & AK1A1 & Alcohol dehydrogenase [NADP $(+)]$ & 0.0364 \\
\hline Q6AXY0 & Q6SA19 & Triosephosphate isomerase & 0.0369 \\
\hline B3RLY8 & ACTG & Actin, cytoplasmic 2 (Gamma-actin) & 0.0485 \\
\hline Q63041 & Q5PQU1 & Kininogen 1 & 0.0669 \\
\hline B7SE64 & ACTH & Actin, gamma-enteric smooth muscle (Alpha-actin-3) & 0.0728 \\
\hline P42123 & HAOX2 & Hydroxyacid oxidase 2 (HAOX2) & 0.0758 \\
\hline Q6AYS7 & Q8R4I6 & Actinin alpha 3, isoform CRA_a (Protein Actn3) & 0.0837 \\
\hline Q38RV9 & MYL9 & Myosin regulatory light polypeptide 9 & 0.0860 \\
\hline Q63707 & Q6AY18 & Protein Sar1a & 0.0916 \\
\hline BOBNJ4 & ACTB & Actin, cytoplasmic 1 (Beta-actin) & 0.0993 \\
\hline Q07936 & MYL6 & Myosin light polypeptide 6 & 0.1023 \\
\hline P07340 & $\mathrm{CO} 3$ & Complement C3 & 0.1044 \\
\hline P29411 & GSTA3 & Glutathione S-transferase alpha-3 & 0.1054 \\
\hline P51647 & KAD3 & GTP:AMP phosphotransferase AK3, mitochondrial & 0.1097 \\
\hline P51635 & ITIH3 & Inter-alpha-trypsin inhibitor heavy chain $\mathrm{H} 3$ & 0.1249 \\
\hline 088989 & BOFTC1VI & Cytochrome c oxidase subunit 2 & 0.1262 \\
\hline Q07523 & MYH10 & Myosin-10 (Cellular myosin heavy chain, type B) & 0.1557 \\
\hline Q9WU21 & VIME & Vimentin & 0.2230 \\
\hline Q9JJ11 & TPIS & Triosephosphate isomerase (TIM) & 0.2276 \\
\hline B7SEC9 & ACTN4 & Alpha-actinin-4 (F-actin cross-linking protein) & 0.2299 \\
\hline E7C9H5 & ANXA2 & Annexin A2 (Annexin II) & 0.2865 \\
\hline Q498M9 & OXDA & D-amino-acid oxidase (DAAO) & 0.2894 \\
\hline E7C9K1 & AT1B1 & Sodium/potassium-transporting ATPase subunit beta-1 & 0.2894 \\
\hline P11517 & D4A8S2 & Protein RGD1307603 (Putative uncharacterized protein RGD1307603_predicted) & 0.3296 \\
\hline E7C9D6 & AL1A1 & Retinal dehydrogenase 1 (RALDH 1) (RalDH1) & 0.4148 \\
\hline P01026 & B7SE64RT & Cytochrome c oxidase subunit 2 & 0.4449 \\
\hline E7C9L4 & BOBMT0 & RCG47746, isoform CRA a (Smooth muscle alpha-actin) & 0.4630 \\
\hline P12346 & E7C9D6LE & Cytochrome coxidase subunit 2 & 0.5169 \\
\hline Q8SEZ5 & TERA & Transitional endoplasmic reticulum ATPase & 0.5599 \\
\hline B7SE77 & ACTN1 & Alpha-actinin-1 (Alpha-actinin cytoskeletal isoform) & 0.5712 \\
\hline E7C9G2 & ALBU & Serum albumin & 0.6050 \\
\hline \multicolumn{4}{|c|}{ Upregulated } \\
\hline Q6P9U5 & Q9WU21 & Glutathione S-transferase Yb4 (EC 2.5.1.18) & 1.7333 \\
\hline Q6IE52 & Q9]ा1 & Alpha-2u globulin & 1.7438 \\
\hline Q6B345 & Q8SEZ5 & Cytochrome $c$ oxidase subunit 2 & 1.8932 \\
\hline Q5BIZ3 & PYRD & Dihydroorotate dehydrogenase (quinone), mitochondrial (DHOdehase) & 2.0340 \\
\hline P46462 & HS90B & Heat shock protein HSP 90-beta & 2.0544 \\
\hline Q8C1W8 & SPA3N & Serine protease inhibitor $\mathrm{A} 3 \mathrm{~N}$ & 2.0544 \\
\hline P19112 & FIBG & Fibrinogen gamma chain & 2.1383 \\
\hline P46418 & HBB2 & Hemoglobin subunit beta-2 (Beta-2-globin) & 2.2255 \\
\hline P34058 & GSTA6 & Glutathione S-transferase $\mathrm{A} 6^{\circ}$ & 2.2933 \\
\hline P08932 & $\operatorname{cox} 2$ & Cytochrome coxidase subunit 2 (Cytochrome c oxidase polypeptide II) & 2.3164 \\
\hline Q5XI38 & Q5BJZ3 & Nicotinamide nucleotide transhydrogenase (Protein Nnt) & 2.3396 \\
\hline Q5U300 & Q498M9 & Similar to glyceraldehyde-3-phosphate dehydrogenase & 2.3632 \\
\hline Q64122 & Q6P9U5 & Ribosomal protein L9 & 2.3869 \\
\hline 064119 & Q6IN37 & GM2 ganglioside activator & 2.4109 \\
\hline P85972 & MUG2 & Murinoglobulin-2 & 2.4843 \\
\hline D4A8S2 & ACY1A & Aminoacylase-1 $\mathrm{A}(\mathrm{N}$-acyl-L-amino-acid amidohydrolase) & 2.6645 \\
\hline P04904 & $\mathrm{CH} 60$ & $60 \mathrm{kDa}$ heat shock protein, mitochondrial & 2.6645 \\
\hline P48500 & HSP7C & Heat shock cognate $71 \mathrm{kDa}$ protein & 2.7183 \\
\hline Q6SA19 & $\mathrm{S} 10 \mathrm{AB}$ & Protein S100-A11 (Calgizzarin) & 2.7183 \\
\hline D2SW96 & ACTS & Actin, alpha skeletal muscle (Alpha-actin-1) & 2.7183 \\
\hline P17751 & F16P1 & Fructose-1,6-bisphosphatase 1 (FBPase 1) & 2.7456 \\
\hline Q5PQU1 & Q38RV9EX & Cytochrome coxidase subunit 2 & 2.8577 \\
\hline P18666 & FIBB & Fibrinogen beta chain & 2.9447 \\
\hline P63039 & LDHB & L-lactate dehydrogenase B chain (LDH-B) & 2.9743 \\
\hline P63259 & LEG1 & Galectin-1 (Gal-1) (14 kDa lectin) & 3.3872 \\
\hline P60711 & KNT2 & T-kininogen 2 (Alpha-1-MAP) (Major acute phase protein) & 3.4212 \\
\hline P68136 & MRLCA & Myosin regulatory light chain RLC-A (Myosin RLC-A) & 3.7810 \\
\hline P68035 & ML12B & Myosin regulatory light chain $12 \mathrm{~B}$ (Myosin RLC-B) & 3.9749 \\
\hline BOBMT0 & A1M & Alpha-1-macroglobulin (Alpha-1-M) & 4.2207 \\
\hline P63269 & $\mathrm{MDHC}$ & Malate dehydrogenase, cytoplasmic & 4.3929 \\
\hline P04762 & CATA & Catalase & 6.7499 \\
\hline Q6RUV5 & RAC1 & Ras-related $\mathrm{C} 3$ botulinum toxin substrate 1 ( $\mathrm{p} 21-\mathrm{Rac} 1)$ & 8.6320 \\
\hline Q63416 & Q5XI38 & Lymphocyte cytosolic protein 1 (Protein Lcp1) & 8.9352 \\
\hline P11762 & D8NU12 & Chromosome partition protein Smc & 9.6794 \\
\hline Q9Z1P2 & VINC & Vinculin (Metavinculin) & 9.7767 \\
\hline P31000 & GSTA5 & Glutathione S-transferase alpha- 5 & 9.8749 \\
\hline Q9JLT0 & TRFE & Serotransferrin (Transferrin) & 10.2779 \\
\hline P09006 & D2SW96 & L-lactate dehydrogenase (EC 1.1.1.27) & 11.8224 \\
\hline Q9QXQ0 & UBA1 & Ubiquitin-like modifier-activating enzyme 1 & 12.0613 \\
\hline Q8R416 & SUCA & Succinyl-CoA ligase [ADP/GDP-forming] subunit alpha, mitochondrial & 12.1825 \\
\hline
\end{tabular}

was decreased when the HUVECs were incubated with $600 \mu \mathrm{M}$ uric acid. However, if the cells were incubated with a medium containing SGR and uric acid, catalase expression was 


\section{Cellular Physiology $\quad$ Cell Physiol Biochem 2014;34:1675-1685 \\ and Biochemistry \begin{tabular}{l|l} 
DOI: 10.1159/000366369 \\
Publisned onlne: November 05, 2014 & $\begin{array}{l}\text { O 2014 S. Karger AG, Basel } \\
\text { www.karger.com/cpb }\end{array}$
\end{tabular} \\ Hong et al.: SGR Reduces Oxidative Stress of ECs via Upregulation of Catalase}

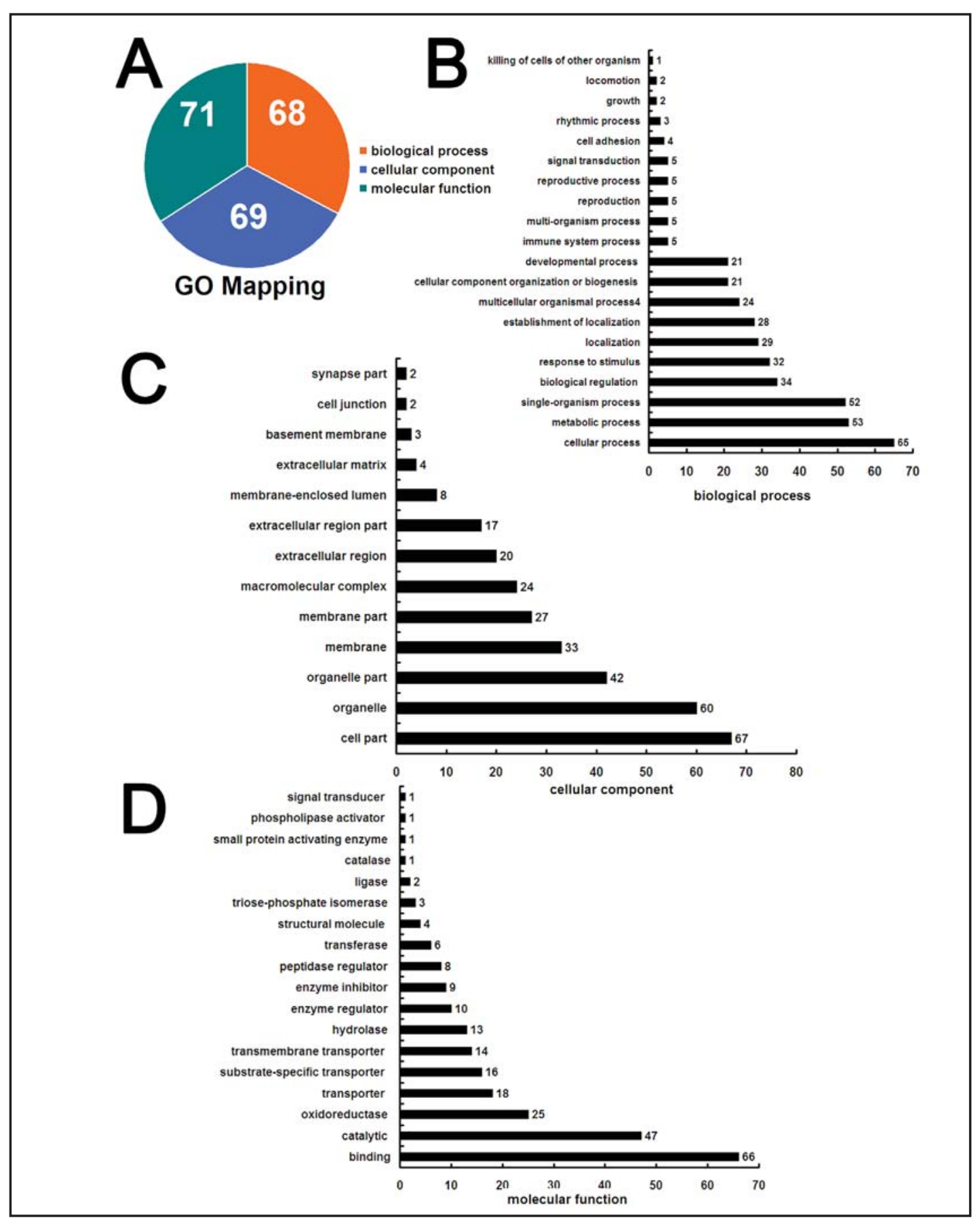

Fig. 1. GO analysis of the differentially expressed proteins. (A) There were 68 proteins that participated in biological processes, 69 proteins belonging to the cellular component domain and 71 proteins that participated in molecular function. (B) The subclassification of the biological processes domain included cellular processes (65), metabolic processes (53), single-organism processes (52), biological regulation (34) and others. (C) The subclassification of the cellular component domain included cell parts (67), organelles (60), organelle parts (42), membrane components (33) and others. (D) The subclassification of the molecular function domain included binding (66), catalytic (47), oxidoreductase (25), transporter (18) and other functions.

increased (Fig. 2C). The total ROS in the cells treated with $600 \mu \mathrm{M}$ uric acid was significantly higher than in the control cells. Nevertheless, when cells were treated with a medium that 
Table 2. Top 10 significant KEGG pathway

\begin{tabular}{lclll}
\hline pathway & Count & p-Value & q-Value & Gene \\
\hline Leukocyte transendothelial migration & 9 & $3.80 \mathrm{E}-13$ & $1.00 \mathrm{E}-11$ & Actb,Actg1,Myl9,Vcl,Mrlc2,Actn1,Actn4,Actn3,Rac1 \\
Regulation of actin cytoskeleton & 10 & $1.90 \mathrm{E}-12$ & $3.20 \mathrm{E}-11$ & Actb,Actg1,Myl9,Vcl,Mrlc2,Actn1,Myh10,Actn4,Actn3,Rac1 \\
Focal adhesion & 9 & $3.00 \mathrm{E}-11$ & $3.10 \mathrm{E}-10$ & Actb,Actg1,Myl9,Vcl,Mrlc2,Actn1,Actn4,Actn3,Rac1 \\
Adherens junction & 7 & $3.60 \mathrm{E}-11$ & $3.10 \mathrm{E}-10$ & Actb,Actg1,Vcl,Actn1,Actn4,Actn3,Rac1 \\
Tight junction & 8 & $4.50 \mathrm{E}-11$ & $3.40 \mathrm{E}-10$ & Actb,Actg1,Myl9,Mrlc2,Actn1,Myh10,Actn4,Actn3 \\
Glycolysis / Gluconeogenesis & 6 & $1.60 \mathrm{E}-08$ & $9.40 \mathrm{E}-08$ & Tpi1,L0C500959,Fbp1,LOC303448,Ldhb,Akr1a1 \\
Complement and coagulation cascades & 4 & $5.4 \mathrm{E}-06$ & 0.000013 & C3,Fgb,Fgg,Kng1 \\
Fructose and mannose metabolism & 3 & 0.000022 & 0.000049 & Tpi1,LOC500959,Fbp1 \\
Systemic lupus erythematosus & 4 & 0.000096 & 0.00021 & C3,Actn1,Actn4,Actn3 \\
Glyoxylate and dicarboxylate metabolism & 2 & 0.00015 & 0.00028 & Mdh1,Hao2 \\
\hline
\end{tabular}

Table 3. Top 10 significant GeneMAPP pathway

\begin{tabular}{lclll}
\hline Pathway & Count & p-Value & q-Value & Gene \\
\hline physiological_process-- & 7 & $1.40 \mathrm{E}-13$ & $7.20 \mathrm{E}-12$ & Actc1,Acta1,Actg1,Myl9,Vim,Actn4,Actn3 \\
Rn_Striated_muscle_contraction & 8 & $6.00 \mathrm{E}-12$ & $7.80 \mathrm{E}-11$ & Actg2,Actc1,Acta1,Actb,Myl9,RGD1309537,Mrlc2,Myh10 \\
Molecular function--motor activity & 9 & $1.60 \mathrm{E}-09$ & $1.00 \mathrm{E}-08$ & Nnt,Ldhb,Dhodh,Cat,Aldh1a1,Akr1a1,Mdh1,Hao2,Dao \\
Molecular Function--oxidoreductase activity & 6 & $8.10 \mathrm{E}-08$ & $4.20 \mathrm{E}-07$ & Alb,Fgb,Mug1,S100a11,Knng11,Fgg \\
Cellular component--extracellular space & 6 & $1.90 \mathrm{E}-07$ & $9.00 \mathrm{E}-07$ & Anxa2,Mug1,Kng111,Itih3,Serpina3n,Pzp \\
Molecular function--enzyme inhibitor activity & 6 & $2.20 \mathrm{E}-07$ & $9.70 \mathrm{E}-07$ & Anxa2,Lcp1,Actn1,Myh10,Actn4,Actn3 \\
Molecular function--cytoskeletal protein binding & 4 & $5.10 \mathrm{E}-07$ & 0.000002 & Tpi1,Fbp1,Ldhb,Mdh1 \\
metabolic_process-- & 6 & $5.90 \mathrm{E}-07$ & 0.0000022 & Actb,Actg1,Myl61,Vcl,Actn1,Rac1 \\
Rn_Glycolysis_and_Gluconeogenesis & 7 & $6.40 \mathrm{E}-07$ & 0.0000022 & Tpi1,LOC500959,Gsta3,LOC501110,Gstm3,Aldh1a1,Suclg1 \\
cellular_process--Rn_Focal_adhesion & 5 & $9.20 \mathrm{E}-07$ & 0.0000029 & Mug1,Kng111,Itih3,Serpina3n,Pzp \\
Biological Process--metabolism & 5 & $9.60 \mathrm{E}-07$ & 0.0000029 & Mug1,Kng1l1,Itih3,Serpina3n,Pzp \\
Molecular function--endopeptidase inhibitor activity & & & \\
Cellular component--protease inhibitor activity & & & & \\
\hline
\end{tabular}

Table 4. GO analysis of catalase (contains $30 \mathrm{GO}$ terms).

\begin{tabular}{lll}
\hline Molecular Function & Biological Process & Cellular Component \\
\hline GO:0004046 aminoacylase activity & GO:0000302 response to reactive oxygen species & GO:0005739 mitochondrion \\
GO:0004096 catalase activity & GO:0006641 triacylglycerol metabolism & GO:0005758 mitochondrial \\
GO:0008083 growth factor activity & GO:0008203 cholesterol metabolism & intermembrane space \\
GO:0020037 heme binding & GO:0008283 cell proliferation & GO:0005764 lysosome \\
GO:0042803 protein & GO:0009060 aerobic respiration & GO:0005777 peroxisome \\
homodimerization activity & GO:0009650 UV protection & GO:0005778 peroxisomal membrane \\
GO:0046872 metal ion binding & GO:0014068 positive regulation of phosphoinositide 3- & GO:0005783 endoplasmic reticulum \\
GO:0050661 NADP binding & kinase cascade & G0:0005794 Golgi apparatus \\
& GO:0020027 hemoglobin metabolism & GO:0005829 cytosol \\
& GO:0032088 inhibition of NF-kappaB transcription factor & GO:0005886 plasma \\
& GO:0042744 hydrogen peroxide catabolism & \\
& GO:0043066 negative regulation of apoptosis & \\
& GO:0051092 activation of NF-kappaB transcription factor & \\
& GO:0051262 protein tetramerization & \\
& GO:0055114 oxidation reduction & \\
& &
\end{tabular}

contained SGR and uric acid, the total ROS generation in the cells was inhibited (Fig. 2D). However, knockdown of catalase resulted in an increase in ROS (Fig. 2E).

\section{Discussion}

From an epidemiologic point of view, hyperuricemia is an increasingly prevalent and pressing clinical problem [26-28]. It has been demonstrated that serum uric acid levels were negatively correlated with the prognosis for metabolic syndrome, diabetes, primary hypertension, atherosclerosis, and chronic kidney disease [29-32]. Smilacis Glabrae Rhizoma (SGR), a component of TCM, has been considered a promising drug for attenuating hyperuricemia and ameliorating nephropathy [33-35], but its mechanism of action is unknown. Our previous study showed that high concentrations of uric acid could alter the expression levels of several kidney proteins [36], many of which might be involved in pathophysiological processes under hyperuricemic conditions. SGR might exert its effects 


\section{Cellular Physiology and Biochemistry}

Cell Physiol Biochem 2014;34:1675-1685

\begin{tabular}{l|l}
\hline DOI: $10.1159 / 000366369$ & (C) 2014 S. Karger AG, Basel
\end{tabular}

www.karger.com/cpb

Hong et al.: SGR Reduces Oxidative Stress of ECs via Upregulation of Catalase

Fig. 2. Validation of the mechanism of SGR alleviating the oxidative stress caused by hyperuricemia. (A) The expression level of catalase in the SGR treatment group was higher than in the hyperuricemia group. ${ }^{*} \mathrm{P}<0.05$, hyperuricemia group versus control; $\uparrow P<0.05$, SGR treatment group versus hyperuricemia group. (B) The ROS level in the SGR treatment group was lower than in the hyperuricemia group. ${ }^{*} \mathrm{P}<0.05$, hyperuricemia versus control; $\dagger P<0.05$, SGR treatment group versus hyperuricemia group. (C) High concentrations of uric acid inhibited the expression of catalase, and SGR alleviated this inhibition. ${ }^{*} \mathrm{P}<0.05$, HUA group versus control; $\dagger \mathrm{P}<0.05$, HUA+SGR group versus HUA group. (D) High concentrations of uric acid increased ROS in HUVEC, and SGR alleviated this increase. ${ }^{*} \mathrm{P}<0.05$, HUA group versus control; $\nmid \mathrm{P}<0.05$, HUA+SGR group versus HUA group. (E) The knockdown of catalase increased the ROS level. $* \mathrm{P}<0.05, \quad \mathrm{HUA}+\mathrm{SGR}+$ siCAT group versus $\mathrm{HUA}+\mathrm{SGR}$ group; $\dagger \mathrm{P}<0.05$, HUA+SGR+siCon versus HUA+SGR+siCAT.

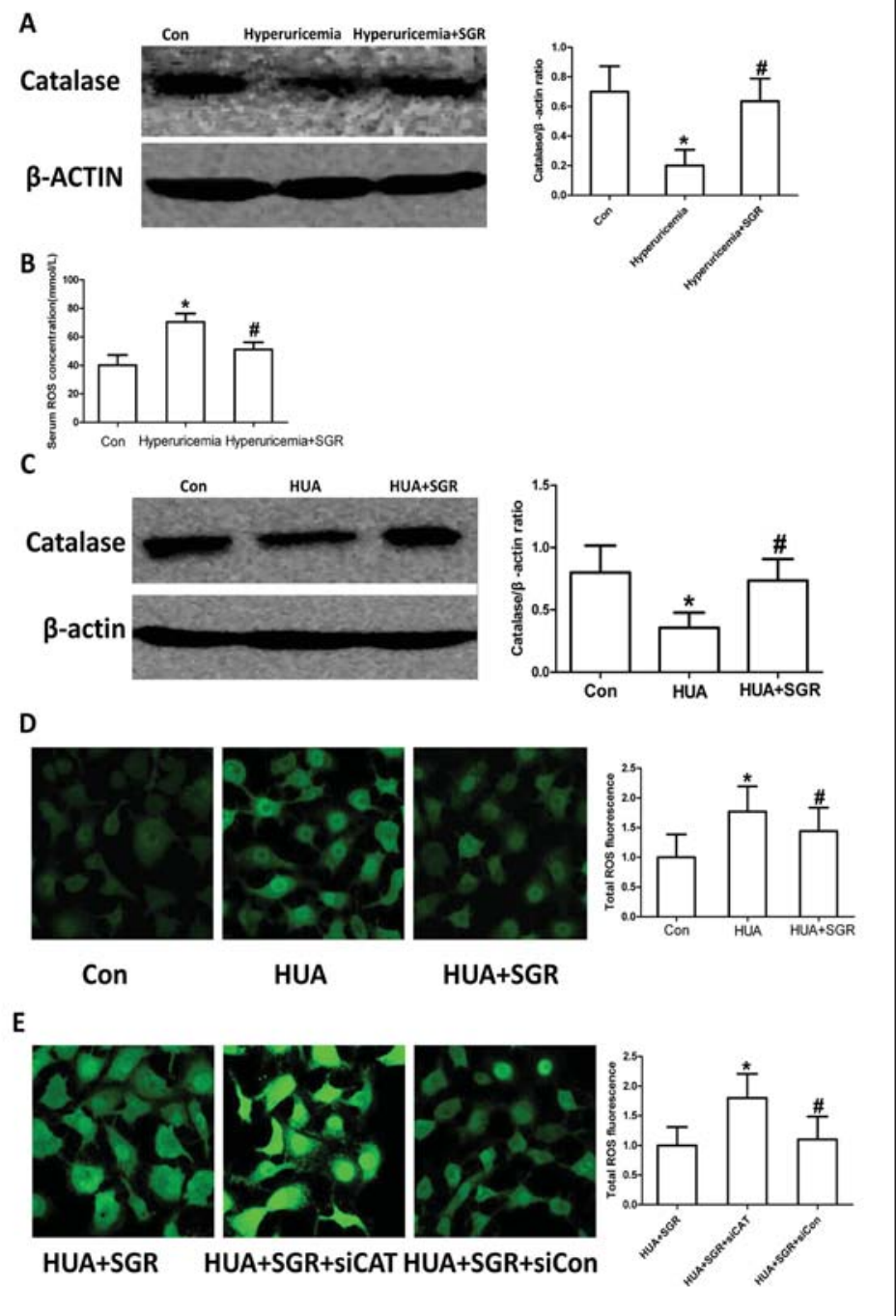

by inhibiting these changes. Therefore, we examined the differentially expressed kidney proteins of a group of rats treated with SGR and compared them to those of an untreated hyperuricemic group. The expression of 72 proteins was significantly different between the two groups, and all of these proteins were subjected to bioinformatic analysis. Under hyperuricemic conditions, ROS production increases significantly [8], and excessive ROS can damage endothelial cells, which are important for maintaining kidney function. It was reported that the kidney damage caused by hyperuricemia was primarily due to oxidative stress and inflammation [37], and bioinformatic analysis has shown that the oxidative stress process was altered in the SGR treatment group. Therefore, we speculated that SGR might exert its effects by inhibiting the oxidative stress process induced by hyperuricemia. Based on gene-pathway and GO-protein network results, we found that, among the differentially expressed proteins, catalase was related to the oxidative stress process and was upregulated approximately 6.4-fold more in the SGR treatment group compared with the HUA group. We confirmed this upregulation with western blotting. Catalase can degrade hydrogen peroxide, an important component of ROS, and therefore reduce oxidative stress. It was demonstrated that hyperuricemia could increase ROS generation systemically [38]; therefore, we sought to determine whether SGR could reduce ROS generation systemically. We examined the serum 


\section{Cellular Physiology and Biochemistry}

Cell Physiol Biochem 2014;34:1675-1685

\begin{tabular}{l|l}
\hline DOI: $10.1159 / 000366369$ & (c) 2014 S. Karger AG, Basel
\end{tabular}

www.karger.com/cpb

Hong et al.: SGR Reduces Oxidative Stress of ECs via Upregulation of Catalase

ROS of the two groups and found that the serum ROS level of the SGR treatment group was lower than that of the hyperuricemia group. Thus, we speculated that SGR could increase catalase expression, which reduced ROS systemically in hyperuricemic mice, indicating that SGR might reduce the oxidative stress caused by hyperuricemia. To validate this hypothesis, we performed an in vitro experiment. Because endothelial cells are among the main targets of oxidative stress caused by hyperuricemia in the kidneys, we used them in our experiment. We determined the expression level of catalase and the total ROS level under high uric acid concentration conditions with and without SGR. The results demonstrated that a high concentration of uric acid reduced the expression level of catalase in endothelial cells, and this decrease could be alleviated by SGR, leading to a reduction in ROS. The knockdown of catalase led to an increase in ROS. These results confirmed our hypothesis. Some studies have found that SGR attenuated hyperuricemia by promoting the excretion of uric acid [39], but it remains unknown whether there is a mechanism that does not rely on increasing the excretion of uric acid. In this study, for the first time, we demonstrated that SGR could alleviate the oxidative stress caused by hyperuricemia by increasing the expression of catalase, and this finding could be the mechanism by which SGR exerts its protective effects on the kidneys.

In conclusion, we demonstrated that SGR could alleviate the oxidative stress caused by hyperuricemia by upregulating catalase expression, and this finding could represent a new application for SGR in the treatment of hyperuricemia.

\section{Acknowledgements}

This work is supported by the Beijing NOVA Program (No. Z121107002512078), the National Basic Research Program of China (973 Program) (No. 2013CB530800), the Chinese National Natural Sciences Foundation (No. 81102673, 81330019 and No. 31170810), and the National High Technology Research and Development Program („863“Program) of China (No. 2012AA02A512).

\section{Disclosure Statement}

The authors have not declared any conflicts of interest

\section{References}

1 Feig DI, Kang DH, Johnson RJ: Uric acid and cardiovascular risk. N Engl J Med 2008;359:1811-1821.

2 Mohandas R, Johnson RJ: Uric acid levels increase risk for new-onset kidney disease. J Am Soc Nephrol 2008;19:2251-2253.

-3 Cameron JS: Uric Acid and renal disease. Nucleosides Nucleotides Nucleic Acids 2006;25:1055-1064.

- Feig DI, Kang DH, Nakagawa T, Mazzali M, Johnson RJ: Uric acid and hypertension. Curr Hypertens Rep 2006;8:111-115.

-5 Wu XH YC, Zhang CF, Anderson S, Zhang YW: Smilax riparia reduces hyperuricemia in mice as a potential treatment of gout. Am J Chin Med 2014;42:257-259.

6 Chen GL WS, Na S, Li L.: Effect of total saponin of dioscorea on uric acid excretion indicators in chronic hyperuricemia rats. Zhongguo Zhong Xi Yi Jie He Za Zhi 2014;34:75-80.

$7 \mathrm{Hu}$ QH, Jiao RQ, Wang X, Lv YZ, Kong LD: Simiao pill ameliorates urate underexcretion and renal dysfunction in hyperuricemic mice. J Ethnopharmacol 2010;128:685-692.

8 Bergamini C, Cicoira M, Rossi A, Vassanelli C: Oxidative stress and hyperuricaemia: pathophysiology, clinical relevance, and therapeutic implications in chronic heart failure. Eur J Heart Fail 2009;11:444-452. 


\section{Cellular Physiology and Biochemistry}

Cell Physiol Biochem 2014;34:1675-1685

\begin{tabular}{l|l}
\hline DOI: $10.1159 / 000366369$ & (C) 2014 S. Karger AG, Basel
\end{tabular}

Published online: November 05, $2014 \quad$ www.karger.com/cpb

Hong et al.: SGR Reduces Oxidative Stress of ECs via Upregulation of Catalase

-9 Hong Q, Qi K, Feng Z, Huang Z, Cui S, Wang L, Fu B, Ding R, Yang J, Chen X, Wu D: Hyperuricemia induces endothelial dysfunction via mitochondrial $\mathrm{Na}+\mathrm{Ca} 2+$ exchanger-mediated mitochondrial calcium overload. Cell Calcium 2012;51:402-410.

- 10 Zhang Y HQ Huang Z, Xue P, Lv Y, Fu B, Chen X, Wu D: ALDR Enhanced Endothelial Injury in Hyperuricemia Screened using SILAC. Cell Physiol Biochem 2014;33:479-490.

11 Papezikova I, Pekarova M, Kolarova H, Klinke A, Lau D, Baldus S, Lojek A, Kubala L: Uric acid modulates vascular endothelial function through the down regulation of nitric oxide production. Free Radic Res 2013;47:82-88.

12 Zoccali C, Maio R, Mallamaci F, Sesti G, Perticone F: Uric acid and endothelial dysfunction in essential hypertension. J Am Soc Nephrol 2006;17:1466-1471.

13 Wang Y, Bao X: Effects of uric acid on endothelial dysfunction in early chronic kidney disease and its mechanisms. Eur J Med Res 2013;18:26.

14 Zhang Y, Yamamoto T, Hisatome I, Li Y, Cheng W, Sun N, Cai B, Huang T, Zhu Y, Li Z, Jing X, Zhou R, Cheng J: Uric acid induces oxidative stress and growth inhibition by activating adenosine monophosphate-activated protein kinase and extracellular signal-regulated kinase signal pathways in pancreatic beta cells. Mol Cell Endocrinol 2013;375:89-96.

15 Preitner F, Laverriere-Loss A, Metref S, Da Costa A, Moret C, Rotman S, Bazin D, Daudon M, Sandt C, Dessombz A, Thorens B: Urate-induced acute renal failure and chronic inflammation in liver-specific Glut9 knockout mice. Am J Physiol Renal Physiol 2013;305:F786-795.

-16 Hiner AN, Hernandez-Ruiz J, Rodriguez-Lopez JN, Garcia-Canovas F, Brisset NC, Smith AT, Arnao MB, Acosta M: Reactions of the class II peroxidases, lignin peroxidase and Arthromyces ramosus peroxidase, with hydrogen peroxide. Catalase-like activity, compound III formation, and enzyme inactivation. J Biol Chem 2002;277:26879-26885.

$\checkmark 17$ Ozyurek M, Bektasoglu B, Guclu K, Apak R: Hydroxyl radical scavenging assay of phenolics and flavonoids with a modified cupric reducing antioxidant capacity (CUPRAC) method using catalase for hydrogen peroxide degradation. Anal Chim Acta 2008;616:196-206.

18 de Groot H, Auferkamp 0, Bramey T, de Groot K, Kirsch M, Korth HG, Petrat F, Sustmann R: Non-oxygenforming pathways of hydrogen peroxide degradation by bovine liver catalase at low hydrogen peroxide fluxes. Free Radic Res 2006;40:67-74.

19 Nagababu E, Chrest FJ, Rifkind JM: Hydrogen-peroxide-induced heme degradation in red blood cells: the protective roles of catalase and glutathione peroxidase. Biochim Biophys Acta 2003;1620:211-217.

20 Yang Z, Xiaohua W, Lei J, Ruoyun T, Mingxia X, Weichun H, Li F, Ping W, Junwei Y: Uric acid increases fibronectin synthesis through upregulation of lysyl oxidase expression in rat renal tubular epithelial cells. Am J Physiol Renal Physiol 2010;299:F336-346.

-21 Sánchez-Lozada LG LM, Cristóbal-García M, García-Arroyo F, Soto V, Cruz-Robles D, Nakagawa T, Yu MA, Kang DH, Johnson RJ: Uric Acid-induced endothelial dysfunction is associated with mitochondrial alterations and decreased intracellular ATP concentrations. Nephron Exp Nephrol 2012;121:e71-78.

22 Wang LY, Hong Q, Lv Y, Feng Z, Zhang XG, Wu LL, Cui SY, Hou K, Su HB, Huang ZY, Wu D, Chen XM: Autophagy can repair endoplasmic reticulum stress damage of the passive Heymann nephritis model as revealed by proteomics analysis. J Proteomics 2012;75:3866-3876.

23 Quan H, Peng X, Liu S, Bo F, Yang L, Huang Z, Li H, Chen X, Di W: Differentially expressed protein profile of renal tubule cell stimulated by elevated uric acid using SILAC coupled to LC-MS. Cell Physiol Biochem 2011;27:91-98.

24 Kanehisa M, Goto S, Kawashima S, Okuno Y, Hattori M: The KEGG resource for deciphering the genome. Nucleic Acids Res 2004;32:D277-280.

-25 Draghici S, Khatri P, Tarca AL, Amin K, Done A, Voichita C, Georgescu C, Romero R: A systems biology approach for pathway level analysis. Genome Res 2007;17:1537-1545.

26 Crittenden DB, Pillinger MH: The year in gout: 2011-2012. Bull NYU Hosp Jt Dis 2012;70:145-151.

27 Robinson PC, Taylor WJ, Merriman TR: Systematic review of the prevalence of gout and hyperuricaemia in Australia. Intern Med J 2012;42:997-1007.

28 Zhu Y PB, Choi HK: Prevalence of gout and hyperuricemia in the US general population: the National Health and Nutrition Examination Survey. Arthritis Rheum 2011;63:3136-3141. 
29 Wiik BP LA HA: Serum uric acid is associated with new-onset diabetes in hypertensive patients with left ventricular hypertrophy: The life study. Am J Hypertens 2010;23:845-851.

-30 Ficociello LH RE NM: High-normal serum uric acid increases risk of early progressive renal function loss in type 1 diabetes: results of a 6-year follow-up. Diabetes Care 2010;33:1337-1343.

- 31 Causevic A SS MDA: Relevance of uric Acid in progression of type 2 diabetes mellitus. Bosn J Basic Med Sci 2010;10:54-59.

-32 Puig JG TR RL: The pathophysiology of hyperuricemia in essential hypertension: a pilot study. Nucleosides Nucleotides Nucleic Acids 2004;23:1197-1199.

- 33 Chen L, Lan Z, Zhou Y, Li F, Zhang X, Zhang C, Yang Z, Li P: Astilbin attenuates hyperuricemia and ameliorates nephropathy in fructose-induced hyperuricemic rats. Planta Med 2011;77:1769-1773.

- 34 Li GS, Jiang WL, Yue XD, Qu GW, Tian JW, Wu J, Fu FH: Effect of astilbin on experimental diabetic nephropathy in vivo and in vitro. Planta Med 2009;75:1470-1475.

-35 Xu WA YL, Pan HY, Shi L, Xu L, Zhang X, Duan JA: Study on the correlation between constituents detected in serum from Rhizoma Smilacis Glabrae and the reduction of uric acid levels in hyperuricemia. J Ethnopharmacol 2013;150:747-754.

-36 Hong Quan XP, Shuwen Liu, Fu Bo, Lv Yang, Zhiyong Huang, Haixia Li, Xiangmei Chen and Wu Di: Differentially Expressed Protein Profile of Renal Tubule Cell Stimulated by Elevated Uric Acid Using SILAC Coupled to LC-MS. Cell Physiol Biochem 2011;27:91-98.

- 37 Viazzi F, Leoncini G, Ratto E, Pontremoli R: Hyperuricemia and Renal Risk. High Blood Press Cardiovasc Prev 2014;10.1007/s40292-014-0042-7

38 Peracoli MT, Bannwart CF, Cristofalo R, Borges VT, Costa RA, Witkin SS, Peracoli JC: Increased reactive oxygen species and tumor necrosis factor-alpha production by monocytes are associated with elevated levels of uric acid in pre-eclamptic women. Am J Reprod Immunol 2011;66:460-467.

-39 Yan H MY, Liu M, Zhou L: The dual actions of Paederia scandens extract as a hypouricemic agent: xanthine oxidase inhibitory activity and uricosuric effect. Planta Med 2008;74:1345-1350. 